\title{
Australia: Basel II Implementation Assessment
}

This paper was prepared based on the information available at the time it was completed on November 6, 2009. The views expressed in this document are those of the staff team and do not necessarily reflect the views of the government of Australia or the Executive Board of the IMF.

The policy of publication of staff reports and other documents by the IMF allows for the deletion of market-sensitive information.

Copies of this report are available to the public from

International Monetary Fund • Publication Services

700 19th Street, N.W. • Washington, D.C. 20431

Telephone: (202) 623-7430 • Telefax: (202) 623-7201

E-mail: publications@imf.org • Internet: http://www.imf.org

\section{International Monetary Fund Washington, D.C.}




\section{Australia}

\section{BASEL II IMPLEMENTATION ASSESSMENT}

NOVEMBER 2009

INTERNATIONAL MONETARY FUND

MONETARY AND CAPITAL MARKETS DEPARTMENT 
Table of Contents

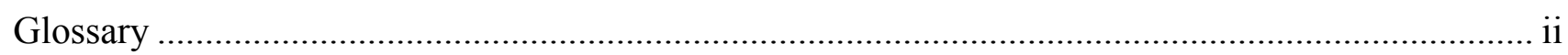

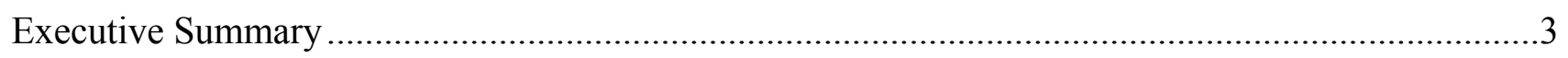

Basel II Implementation in Australia-An Assessment .................................................................5

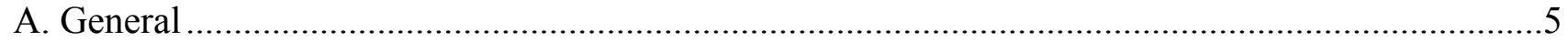

B. Institutional and Macroprudential Setting, Market Structure Overview .......................................5

C. Relation between Basel Core Principles and Basel II Implementation.......................................6

D. General Preconditions Relevant for Basel II Implementation .................................................

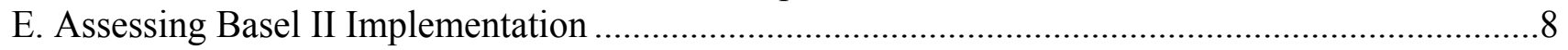

I. Strategy, Plans, Process, Governance, and Resources ..................................................... 8

II. Assessing the Capital Adequacy Framework Overall ......................................................... 11

III. Assessing Pillar 1 Variants ........................................................................................................ 14

Standardized approaches to credit risk ................................................................................ 15

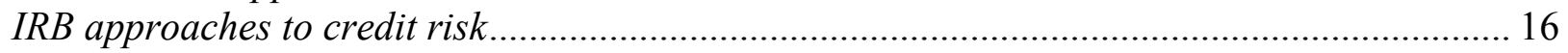

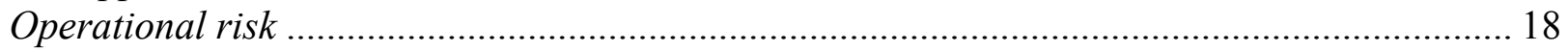

Market risk and interest rate risk in the banking book ..................................................... 19

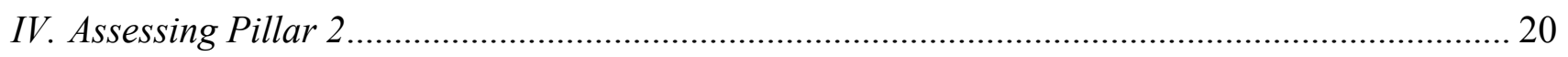

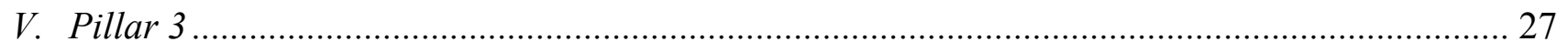

VI. Home-Host Relations for Implementing Basel II.......................................................... 28 


\section{GLOSSARY}

\begin{tabular}{|c|c|}
\hline $\mathrm{ABA}$ & Australian Bankers' Association \\
\hline ADI & Authorized Deposit-taking Institution \\
\hline APRA & Australian Prudential Regulation Authority \\
\hline AMA & Advanced Measurement Approaches \\
\hline ASA & Alternative Standardized Approach \\
\hline BAU & Business as Usual \\
\hline BCBS & Basel Committee for Banking Supervision \\
\hline $\mathrm{BCP}$ & Basel Core Principles \\
\hline BIA & Basic Indicator Approach \\
\hline CRM & Credit Risk Mitigation \\
\hline ECAI & External Credit Assessment Institution \\
\hline ICAAP & Internal Capital Adequacy Assessment Process \\
\hline ILG & International Liaison Group \\
\hline IRRBB & Interest Rate Risk in the Banking Book \\
\hline FSAP & Financial Sector Assessment Program \\
\hline GDP & Gross Domestic Product \\
\hline IFRS & International Financial Reporting Standards \\
\hline IMF & International Monetary Fund \\
\hline IRB & Internal Ratings-Based Approach \\
\hline PCR & Prudential Capital Ratio \\
\hline QIS & Quantitative Impact Studies \\
\hline $\mathrm{RBA}$ & Reserve Bank of Australia \\
\hline SA & The Standardized Approach \\
\hline VaR & Value at Risk \\
\hline
\end{tabular}




\section{EXECUTIVE SUMMARY}

APRA operates a sound supervisory system that meets Basel II requirements and builds on the robust regulatory and supervisory process already in place prior to Basel II. There is sufficient evidence of its effectiveness in promoting a well-capitalized banking system, both on an ongoing basis and in response to specific events, such as the recent global financial crisis.

APRA allocated sufficient resources, including highly skilled staff, prior to the Basel II start date, and the outcome has been a robust and high-quality implementation that has built upon and substantially strengthened the risk-management capabilities of the major banks. The quality of leadership and commitment by all involved has been instrumental in the success of this major implementation effort.

APRA's analysis of the adequacy of capital for systemically relevant banks is sound. It has a good understanding of what drives differences in capital levels between the various banks and has quality processes in place to satisfy itself that these are broadly reflective of risk. APRA is encouraged to pursue its agenda of continued focus on the analysis of impacts for IRB and AMA banks, including scenario and stress testing. This will ensure that APRA has an up-to-date understanding of how capital levels may respond to various stress events and will also enable it to have better information on which to base future judgments of the adequacy of capital in the system.

Basel II places additional ongoing demands on resources, and these can be expected to rise further with the enhancements in the regulatory framework being proposed internationally. APRA should review the workload, as it gains experience with Basel II, and augment its resources accordingly.

As in other countries, there are a few areas where APRA can build on initiatives underway. That would further increase the effectiveness of implementation, promote ongoing risk-management improvements in banks and ensure that its goals of a wellcapitalized banking system continue to be met. It will be important for APRA to continue to undertake increasingly complex work (drill down reviews for advanced banks, stress testing, assessment of Pillar 2 risks, and economic capital models, etc.) to assure itself that banks remain well capitalized relative to their risks.

APRA has done well to take national circumstances and experiences into account to make the appropriate choices of national discretion items in Pillar 1 of the Basel II framework. This has led to the view that reported minimum Tier 1 capital ratios for the major banks are lower than would otherwise be the case. However, actual levels of capital held by banks in various jurisdictions are affected by many factors. Great care is needed in interpreting these results. APRA is correct to distance itself from the type of specific comparison between countries that banks are publishing. 
APRA has also made several choices to simplify implementation for the smaller banks, building societies, and credit unions, representing nearly a third of banking system assets. Most notable is adoption of the ASA for operational risk and a simplified Pillar 3 disclosure regime. While these choices are consistent with the Basel II framework and appropriate for small entities, APRA is encouraged to consider a few additional requirements for mid-size banks in this group for operational risk and Pillar 3 to reflect their importance in the system.

APRA and banks have done a good job in the initial implementation of Pillar 3, which is ahead of practices elsewhere in some regards. There is evidence of increasing use by analysts of this information, though there continues to be interest in more consistency. There may be opportunities to encourage some further simple explanation of the disclosures by smaller banks and some further ease of access to the disclosures of larger banks.

\section{Box 1. Summary of Recommendations}

The mission made the following recommendations for APRA to further enhance effectiveness of Basel II implementation:

Conduct self-assessment against the revised (2006) BCP methodology to identify and address any gaps in Basel II /risk-management-related principles.

Review the ongoing and projected workload related to supervisory tasks introduced by Basel II and to augment resources accordingly.

Include in supervisory plans periodic detailed drill-down (re-validation and replication) reviews on some portfolios and plans for periodic cross-system reviews of selected key IRB parameters.

Enhance (i) reviews of ADI economic capital models; (ii) APRA and ADI analysis of impacts of the economic cycle on available and required capital; and (iii) APRA and ADI stress-testing capabilities, building on work done to date.

Strengthen channels of communication and consultation on a cross-industry basis.

Communicate an expectation of independent IRB validation units in banks.

Monitor AMA results in comparison to other AMA banks globally to confirm its overall assessment on the reasonableness of impacts. Undertake work on specifying qualifying criteria for use of ASA and reassess the adoption of ASA by the larger standardized banks.

Prioritize the revision of its prudential standard on liquidity.

Review exemption from quarterly Pillar 3 disclosure requirements for standardized banks to (i) require sufficient information to enable the disclosure to be placed in context; (ii) reconsider the summary nature of disclosure for listed and mid-size banks; and (iii) encourage banks to make disclosures more prominent. 


\title{
BASEL II IMPLEMENTATION In AUSTRALIA-An ASSESSMENT
}

\begin{abstract}
A. General
1. This Basel II assessment is conducted in accordance with "Implementation of Basel II, Assessment Criteria," a document jointly prepared by the International Monetary Fund and the World Bank with the assistance of members of the Basel Committee's International Liaison Group (ILG), a sub-committee of BCBS. This assessment of the implementation in Australia was carried out by an IMF mission that visited Sydney during May 5-12, 2009. ${ }^{1}$ This assessment takes into account both the basis for regulation and supervision, such as the institutional framework, laws, and guidelines, and their implementation by the authorities as well as in the supervised institutions.
\end{abstract}

2. This assessment is conducted separately from a BCP assessment and separate ratings are not provided with respect to each Basel II assessment criteria. It is not a full, detailed verification of Basel II compliance. In particular, it focuses on detailed rules only to the extent necessary to confirm the assessors' ability to rely on the self-assessment provided by the authorities. While this assessment includes observations and recommendations related to supervisory practices, it did not explicitly consider the related Core Principles, such as those covering risk management, supervisory practices, or liquidity. Some of these, such as those related to liquidity, would be of particular importance in a BCP assessment, given the structure of Australian banks' balance sheets.

3. The assessors received all required information and had access to all persons necessary to complete the assessment, and are grateful to APRA for the willing assistance that they received. APRA provided a detailed self-assessment, questionnaires, and supporting documentation on guidance and standards prior to the visit. The assessment team conducted preliminary analysis of this material and other relevant documents, including recent Article IV assessments and a BCP self-assessment of the authorities conducted in 2006. The team spent one week on-site and met with APRA staff, industry representatives, an auditor firm, a rating agency, and RBA. These meetings focused on selected matters identified beforehand and communicated to APRA in advance, and on issues that became apparent while on-site.

\section{B. Institutional and Macroprudential Setting, Market Structure Overview}

4. The 2006 FSAP concluded that, overall, the Australian financial system was strong and stable and the financial regulatory and supervisory structure sound, with high compliance with international standards. The Australian Prudential Regulation Authority (APRA), established in July 1998, is the prudential regulator of the Australian financial

\footnotetext{
${ }^{1}$ Aditya Narain (MCM, Mission Chief); Nicholas Le Pan, ex-Superintendent of OSFI, Canada and ex-Chair of the Accord Implementation Group of the Basel Committee on Banking Supervision; and Carel Oosthuizen, formerly South African Reserve Bank.
} 
services industry. It oversees banks, credit unions, building societies, general insurance and reinsurance companies, life insurance, friendly societies, and most assets of the superannuation industry. APRA is funded largely by the industries that it supervises. It currently supervises institutions holding approximately US\$3.4 trillion in assets for 21 million Australian depositors, policyholders, and superannuation fund members. APRA also acts as a national statistical agency for the Australian financial sector and plays a role in preserving the integrity of Australia's retirement incomes policy. ASIC (Australian Securities and Investments Commission) regulates the financial markets and market-conduct issues.

5. The banking system represents nearly half of the total financial sector assets. There are currently 58 banks, 12 building societies, and 133 credit unions operating in Australia. ${ }^{2}$ In turn, the banking system is dominated by the four majors, which together account for over two-thirds of all resident bank assets. The key vulnerabilities in the banking system identified by the FSAP are (i) its dependence on wholesale funding, at 50 percent of total funding sources; and (ii) the overall lack of diversification, with half the book being residential mortgages.

\section{Relation between Basel Core Principles and Basel II Implementation}

6. In 2005, APRA undertook a self-assessment against the 1997 version of the Basel Core Principles in preparation for the 2006 FSAP. The FSAP had found the Australian system to exhibit a high overall level of compliance with the BCP. Most prudential regulations and their implementation were deemed to be of a very high standard. Prudential requirements for capital and capital adequacy ratios (CAR) were in line with international best practices, a factor which was seen to facilitate the adoption of Basel II. The approach to supervision was at the leading edge of the current approaches to risk-based supervision, and the overall quality of supervision was judged to be good with some variation in quality among various divisions and teams. Noncompliance with the $\mathrm{BCP}$ was reflected mainly in the areas related to AML/CFT (which is not a statutory responsibility of APRA) and the boundaries between deposit-taking activities of regulated and nonregulated entities. Work has been undertaken since the 2006 FSAP to improve compliance in the identified areas.

7. APRA participated in the work of drafting the revised (2007) version of the BCP and the associated methodology. However, it has not undertaken a formal self-assessment against the revised principles. Since many of the revisions are related to updating of risk measurement and management practices arising out of the introduction of the Basel II framework (for example, the new principles on comprehensive risk management (CP 7); interest rate risk in the banking book, liquidity, and operational risks (CP 14-16)); identifying and addressing any gaps in these areas would be an important supplement to

\footnotetext{
${ }^{2}$ As a collective term, these entities are referred to as ADIs (authorized deposit-taking institutions) in the Australian context. For the purpose of this report, the terms 'ADI' and 'bank' have been used interchangeably.
} 
the efforts that have been made toward robust implementation of Basel II. Based on discussions with APRA, the mission concluded that work was still ongoing in this regard.

\section{General Preconditions Relevant for Basel II Implementation}

8. The preconditions for effective banking supervision and, hence, for implementation of Basel II, are well established in Australia. As noted by the FSAP, the country has implemented a wide range of structural reforms and strengthening of monetary and fiscal policy frameworks over the past two decades. This resulted in a 15 -year period of economic expansion beginning in 1992. The financial system has weathered the global financial crisis relatively well compared to many other developed economies, bolstered by the government guarantees on deposits and wholesale funding. However, bank profitability has come under strain in recent periods, lending growth has slowed, and the level of problem loans has registered a sharp increase; although levels continue to remain low overall, compared to the downturn of the 1990s. Both the RBA and APRA took various actions to lean against the run-up in property prices, including, in APRA's case, increasing the capital charge on 'low-doc' loans, so that Australian banks have not faced the associated issues that have been present in other countries.

9. Australia's legal infrastructure is good and is comparable to other industrial countries. The Commonwealth of Australia follows a federal system of government and the constitution sets out the basis for relations between the Commonwealth and the states and provides the system of separation of powers. The legal framework is founded on English common law and equitable principles. APRA operates in accordance with the Commonwealth law, and the winding up of banks is carried out under the provisions of the Commonwealth law. The Corporations Act deals with corporate insolvency and focuses on the efficient winding up of companies, orderly realization of assets, and equitable distributions of proceeds.

10. Australia adopted the IFRS with effect from January 2005, and adopts changes as they occur. Some country-specific accounting standards have also been retained. APRA's objective is to align prudential and reporting standards with Australian accounting standards to the extent possible, unless there are sound prudential reasons not to do so. The accounting profession is well established and recognized internationally. Oversight of auditors is provided by ASIC and professional accounting bodies. Auditing standards are established by the Auditing and Assurance Standards Board and based on International Standards of Auditing.

11. Disclosure standards are well developed. Listed companies are subject to a modern, continuous disclosure regime. The majority of smaller ADIs is not listed, but is subject to financial disclosure requirements under the Corporations Act 2001. From September 30, 2008, these institutions are now required to release (Pillar 3) prudential disclosures. APRA regularly publishes financial statement information on the supervised entities. 
12. There have been no private sector bank failures for many decades and the community has a presumption that failure to pay bank creditors would not be permitted by the authorities. There is ongoing consolidation in the industry through mergers and acquisitions. APRA has a broad range of powers to deal with problem institutions. The RBA has a policy to provide LOLR facilities to illiquid but solvent institutions, and has used these during the financial turmoil. There is no explicit deposit insurance, though in the wake of the current crisis, a temporary government guarantee has been provided on all deposits ${ }^{3}$ and wholesale debt funding. In late 2008, the Australian Government enacted a Financial Claims Scheme, to be administered by APRA, which is intended to protect retail depositors. The retail deposit guarantee will operate for a period of three years and will be reviewed at the end of that period.

\section{E. Assessing Basel II Implementation}

\section{Strategy, plans, process, governance, and resources}

13. APRA's vision is to be a world class integrated prudential supervisor recognized for its leadership, professionalism, and innovation. Its supervisory approach is forwardlooking, primarily risk-based, consultative, consistent, and in line with international best practice. This approach also recognizes that management and Boards of supervised institutions are primarily responsible for financial soundness.

14. In June 2003, APRA formally announced its decision to implement Basel II in its totality and, with limited exceptions as mentioned in this report, APRA does not permit sub-standard deviations from Basel II. An external program director with extensive banking supervision experience was appointed to oversee the implementation of Basel II and an APRA-wide central projects office was established. As is to be expected and borne out by experience of other early implementers, at that time the level of maturity of APRA's program/project management capacity was relatively low. During 2004, formal program/project management documentation was formulated and a dedicated full-time project manager was appointed to the program in 2005.

15. APRA's program/project management methodology improved significantly over the life of the Basel II program and those sub-projects that began later in the program had the benefit of access to a more mature program/project management methodology. APRA has subjected its project-management process to internal and external reviews and is cognizant of applying sound project management early on in future projects of such scale.

16. APRA is responsible for the process of developing and maintaining the regulatory framework, which is constituted of what are referred to as prudential standards and associated prudential practice guides. The draft prudential standards and associated prudential practice guides to give effect to the implementation of Basel II went through a rigorous internal review process involving relevant subject-matter experts and APRA's

\footnotetext{
${ }^{3} \mathrm{~A}$ fee is applicable to that component of a deposit in excess of AUD $\$ 1$ million.
} 
policy development unit; the Basel II Steering Group (BSG) for endorsement; and the APRA Executive Group for approval. They were also subject to public consultation. Following approval by APRA's Executive Group, each of the prudential standards and practice guides was released for at least one round of public consultation before finalization, with a number of the more complex standards being released for two rounds of public consultation.

17. APRA's work in relation to accreditation began prior to the submission of formal accreditation applications by ADIs, more than two years before Basel II implementation. Similar to the policy development work, the accreditation work spanned the life of the program. APRA assessed ADIs' applications for accreditation to use the IRB approach to credit risk, an AMA for operational risk and an internal model for the calculation of the capital charge for IRRBB. In addition, regular contact with ADIs provided opportunities to clarify interpretation and expectations regarding Basel II requirements.

18. APRA generally funds itself by levies on industry. The overall budget of APRA is agreed with government and headcount has remained steady at around 570 over the past five years. Over the past few years, within this total, the number of staff in specialist/technical positions covering all APRA-regulated industries has risen considerably. Recently, an additional temporary allocation of 30 FTE was added, funded by government, in order to assist in dealing with the financial crisis.

19. A dedicated Basel II team was built up in APRA starting in 2003. It peaked in 2008 at 16.4 staff (full-time equivalent). This included resources for accreditation and quantitative analysis, policy development, and development of the Basel II reporting requirements and system. As part of the shift to the BAU environment, the dedicated team was disbanded in 2008 and staff reallocated to other divisions. Turnover has been within acceptable levels.

20. Frontline supervisors, in particular, those from the Diversified Institutions Division, also participated in APRA's Basel II implementation project. Overall, APRA estimates that approximately 75 staff across APRA was involved in the initial implementation of Basel II. More have attended training. APRA also made some use of outside experts. As has occurred in other countries, accreditation work on Basel II substituted to some degree for other supervisory work.

21. Implementation of Basel II was accommodated within the overall APRA headcount, in part by use of what would otherwise have been vacant positions. APRA and the banking industry agreed that the level of financial resources required for the implementation of Basel II in Australia was beyond that funded by normal industry levies. To ensure an appropriate allocation of costs, APRA imposed specific Basel II charges on those ADIs that detailed their intention to use the advanced Basel II approaches. This meant that decisions to build up Basel II staff were not constrained by allocation of costs to industry more generally. Given the heightened level of supervisory resources necessary for the ongoing supervision of those ADIs that are using the advanced approaches, it is envisaged that APRA will continue to recoup its associated costs. 
22. APRA is not new to the risk-specialist concept and has experience with the matrix-type approach to supervision that this entails. It is aware of the ongoing need to promote coordination among the groups.

23. Many other countries implementing Basel II have found that 'business as usual' after the start date is not the same as before. Pillar 1 and Pillar 2 place additional ongoing demands on supervisory staff. These can be expected to rise further with focus being mandated internationally on such matters as stress testing. There is also Basel II policy development work internationally that will need to be implemented in Australia. And it will be important for APRA to undertake sufficient Basel II-related supervisory work to assure itself that banks remain well capitalized relative to their risks. As noted elsewhere in this report, the mission believes that, as in a number of other countries, a limited amount of additional Basel II- related supervisory work , beyond that currently planned, is likely to be required. APRA should review the likely ongoing workload as it gains experience with Basel II and increases its resources accordingly.

24. In the view of APRA, there was ongoing and effective communication between APRA and the banking industry in relation to Basel II. From its inception, APRA was working with the major banks on Basel II-related matters and was also providing updates to the industry on Basel II issues through its annual reports and other publications.

25. In the light of comments from both APRA and the industry, it would appear that there is a continuing need for communication, guidance, feedback, and consultation, particularly on a cross-industry basis. It is recommended that APRA place emphasis on this aspect. The ABA has also strengthened its organization and resources to play the role of an industry sounding board, and the proposed enhancements to the Basel II framework being deliberated by the Basel Committee will provide an opportunity to foster an enhanced consultation process with the industry.

26. Various modules of APRA's documentation pertaining to its supervisory process were updated for Basel II implementation, including credit risk, operational risk, risk governance, and capital. To assist supervisors of ADIs using the advanced approaches, supervisory guides were updated and a supervision schedule developed. This schedule provides guidance on the types of visits that are necessary to supervise ADIs using the advanced approaches, along with recommended frequencies and resources to undertake the activity.

27. APRA received eight applications from ADIs seeking approval to use the advanced approaches from January 1, 2008. Of these applications, APRA accredited four ADIs to use both the IRB approach to credit risk and an AMA approach for operational risk from January 1, 2008. Two ADIs were accredited to use only an AMA approach to operational risk from that same date. In this case, APRA's policy is that there is no capital relief until the relevant ADI is fully accredited. Two ADIs did not receive IRB or AMA approval. 
28. APRA's prudential standards restrict an ADI's choice of approaches insofar as they require an ADI that applies to use an advanced approach for one risk class (credit risk, operational risk, or IRRBB) to apply concurrently to use advanced approaches across all risk classes.

29. ADIs that do not receive accreditation for the advanced approaches must use the standardized approaches.

30. APRA supervisors have an appropriate level of experience and expertise to analyze ADIs' plans for and implementation of Basel II and, where required, challenge them. The APRA framework for prudential supervision helps to ensure that supervisors undertake adequate analysis and review. Examples of effective challenge are encompassed in the benchmarking process undertaken during the accreditation process and the determination to set the floor on LGD estimates at 20 percent for residential mortgage portfolios, as opposed to 10 percent, in view of the lack of evidence to justify the latter level.

\section{Assessing the capital adequacy framework overall}

31. APRA has put in place clear rules and guidance covering such matters as scope of application, minimum capital ratio required, the various approaches available to banks, and the approval process. Beyond the requirements detailed in the prudential standards, APRA has more general expectations of any ADI applying for approval for the advanced approaches. These expectations relate to the extent to which the use of risk-based capital and associated risk-adjusted performance measurement permeates the management of the ADI's business. A clear demonstration that an ADI's Board and management are both willing and able to incorporate the quantification of risk into their management processes and decision making is essential to the credibility of minimum regulatory capital figures determined by the ADI, using the IRB and AMA approaches. Discussions that the mission had with supervisory staff and banks confirmed that this was indeed occurring and confirmed the robustness of APRA's approach to verification.

32. Australian ADIs participated in all but one (i.e., QIS 4) of the QIS exercises and APRA staff was also involved in the BCBS's analysis of the results of two QIS exercises. APRA collected parallel-run data during 2006 and 2007 from the applicant-advanced ADIs and undertook analysis of this data. A data collection exercise involving a limited number of ADIs that would be using the standardized approaches was also undertaken in 2007.

33. Initial QIS results suggested major reductions in minimum capital for Australian banks (in excess of 25 percent) beyond what the authorities were comfortable with, based on their understanding of the risks in the system. This led to extensive dialogue with banks during the application/accreditation period to ensure that various risk estimates were reasonable, and to several policy choices as to how the Basel II framework was to be implemented in Australia. Those choices were, however, grounded in sound analysis of risk and the Australian market and not merely on a desire to arbitrarily fill a capital gap. 
34. Parallel run information for the five major banks in 2008 showed reductions in capital averaging in the 5 percent to 7 percent range for most banks, with one bank estimating a larger reduction and one bank an increase. For smaller and mid-sized banks the overall impact was not materially different from Basel I. APRA chose not to apply reduced risk weights for retail and commercial property loans. This meant that the reductions in credit risk capital were limited and essentially offset by operational risk capital charges.

35. As in other jurisdictions, the impacts for major banks were composed of reductions in credit risk capital (total capital) in the 15 percent to 20 percent range, offset by the addition of operational risk ( +3 percent to +5 percent of capital) and by other deductions from capital, which can be material in Australia (particularly in computing Tier 1). In addition, for major Australian banks, EL is higher than provisions (in part because of the use of robust measures for downturn LGDs). Accordingly, there are material reductions in capital ratios from this effect.

36. With respect to scope of application, APRA's prudential standards are consistent with the Basel II Framework. Basel II Capital requirements apply to all ADIs (including internationally active ADIs) at two levels. The first is at the level of the ADI itself, while the second is at the level of the banking group. In a number of cases (e.g., for minority investments), APRA has chosen options that would tend to increase capital requirements.

37. APRA's approach for deductions of investments in nonbanking financial entities and commercial entities generally follow the Basel II framework (investments in insurance entities are deducted). Generally, minority investments are deducted rather than risk-weighted. Funds management entities are not generally included in the consolidation of the banking group to which Basel II applies, which differs somewhat from the treatment elsewhere, in part because a number of these are subsidiaries of insurance entities within banking groups rather than directly part of the banking group.

38. APRA's approach to the definition of capital is consistent with the Basel II framework. Tier 3 capital is not recognized. In several areas, APRA's choices of national discretion items that are deducted from capital would result in less available capital than is the case in a range of other countries.

39. As in other jurisdictions, APRA, banks, and the analyst community generally focus on Tier 1 capital. Measures of tangible common equity are not currently being disclosed by banks.

40. APRA requires ADIs, using the IRB and AMA approaches, to concurrently report under the Basel I and Basel II requirements, with a 90 percent floor on Basel II capital relative to Basel I. Unlike the Basel II framework, APRA did not adopt the lower 80 percent floor and has not included a formal end date for its application pending a review in 2009 of experience with the advanced Basel II approaches. APRA indicated that changes are unlikely in the short term until developments internationally with leverage ratios that can act as a floor, are clearer. Some banks indicated a desire to cease having to compute Basel I figures on an ongoing basis. 
41. Major banks have demonstrated access to capital. Recently, larger and mid-sized banks have raised material amounts of high-quality capital and have taken actions, such as lowering dividends, to bolster their positions in the face of rising impairments and other factors. Banks have also taken advantage of the government's temporary guarantee of wholesale funding to access these markets and lengthen the term of this funding.

42. The mission had extensive discussions with APRA about the level of capital for major banks and the nature of APRA's analysis and thought processes to satisfy themselves that it is adequate and related to risks in the Australian banking system. Currently, the four major banks, which APRA regards as systemically important and which are rated AA, operate with Tier 1 capital in the 8 percent range, slightly higher than the trend over the past few years. Prima facie, this appears lower than might be expected based on international comparisons. Banks and APRA believe that there may well be material adverse movements in required minimum capital levels (and capital available) as the economic cycle worsens. Little deterioration has been seen to date and, as in a range of other jurisdictions, the estimates of this effect could be improved through additional stress testing.

43. APRA has performed a variety of analyses to satisfy itself as to the level of capital held by banks. In addition to micro analysis of individual institutions' capital relative to their risks, and reviews of banks' stress tests that have recently commenced in an in-depth way, APRA has performed high-level analyses of the impact of mild, moderate, and severe deterioration in the economy.

44. The mission believes these approaches are reasonable and APRA's analysis of the adequacy of capital levels for systemically relevant banks is sound. It encourages APRA to pursue its agenda of continued focus on banks, and its own scenario and stress testing, to ensure it has the best information available on which to base judgments of the adequacy of capital in the system. Requiring banks to perform analyses of the likely cyclicality of their capital would also be useful to enhance APRA's understanding of the dynamics of their system under Basel II. This should include assessments of how the EL-provisions difference may move under various scenarios.

45. The mission is satisfied that APRA has a very good understanding of what drives differences in capital levels between the various banks, and has quality processes in place to satisfy itself that these are broadly reflective of risk.

46. While reported Tier 1 ratios of major banks are in the 8 percent range, which appears less than peers elsewhere, banks and APRA believe that their choice of national discretion items in Pillar 1 of the Basel II framework means that reported Tier 1 capital is materially lower than would be the case elsewhere. The mission believes that the point is valid in concept and affects the ability to judge the adequacy of capital, overall, based on simple international comparisons. However, actual levels of capital held by banks in various jurisdictions are affected by many factors, including both pillars of Basel II and market, and rating agency dynamics. For example, while one country may make certain 'conservative' choices in Pillar 1, another might informally expect a higher buffer over its required minimum and achieve this result through different means. 
47. Banks have commissioned and, in certain cases, published comparisons with rules in several other countries and claim that, as a rule of thumb, these differences overall could result in Tier 1 capital differences of 100-350 basis points. Major banks regularly report such comparisons, motivated by a desire to make sure the analyst and rating agency community have an appropriate understanding of their position relative to international peers.

48. Great care is needed with respect to these comparisons in this area and APRA is correct to distance itself from this. However, certain recent official publications have started to refer to this or to stylize APRA's overall approach to capital as "conservative," in recognition of these kinds of comparisons. If APRA is going to rely increasingly on these sorts of analysis to help it internally to judge the adequacy of capital in the Australian banking system, then it will need to perform additional analysis to better understand the full range of differences affecting both pillars of Basel II. That would include understanding supervisory expectations in various other countries for key risk parameters above their stated Pillar 1 minimums and what drives banks' choices of the capital they wish to hold, given different countries' approaches to ICAAPs and supervisory expectations/requirements for capital above the minimum.

49. APRA has noted that markets are increasingly demanding higher high-quality capital than previously. In the short term, the risk is that this trend can reduce bank's willingness to support robust lending growth, as senior APRA officials have noted publicly. However, in the medium term, it is possible that recent market events will increase what markets and regulators judge as necessary capital for systemically important banks. That may have an impact on how APRA judges the target levels for its banks and this will need to be monitored closely.

\section{Assessing Pillar 1 variants}

50. The mission team reviewed the self-assessment of rules and the process that was followed to approve applications for IRB and AMA. They also reviewed selected potential issues in the implementation of a standardized approach focusing on the authorities' approach to key risk-weight decisions, how banks' accuracy in applying and calculating the standardized framework is to be verified, and how the new credit risk mitigation rules are being implemented, verified, and monitored.

51. The economic downturn during the early 1990s resulted in the Australian banking system suffering severe credit losses. As a consequence, there was an acute awareness of the need for sound credit risk management and a concomitant commitment toward best practice in credit risk management. As a result, by the late 1990s, the larger Australian banks were active in quantifying credit risk and incorporating credit risk in capital management by means of economic capital models.

52. APRA understood the benefit of sound credit risk management and was similarly committed toward best practice in credit risk management. As a consequence, soon after its establishment in 1998, APRA informed itself, including through the studying of publications of the Basel Committee on Banking Supervision and interacting with the 
ADIs, on leading practices in credit risk management and capital management, including economic capital models.

\section{Standardized approaches to credit risk}

53. APRA has not permitted the use of the simplified standardized approach. The standardized approach (SA) to credit risk has been implemented by all non-IRB banks, including all locally incorporated subsidiaries of foreign-owned banks. One hundred and sixty-one ADIs (representing 25 percent of bank assets) and two wholly-owned subsidiaries of banks on advanced approaches (representing 7 percent of bank assets) are currently on the SA.

54. The risk weights specified by APRA are aligned with the Basel II framework. In keeping with the philosophy of the Basel II framework, APRA has taken national circumstances, practices, and loss experience into account in requiring risk weights higher than the minimum in the Basel II framework for retail exposures (100 percent instead of 75 percent); listed and nonlisted equities (300 percent to 400 percent); residential properties (35 percent to 100 percent based on LTV ratios); and retail margin loans (20 percent). These measures, as well as some of the national discretions that have been exercised, can result in delivering higher Pillar I capital requirements than the application of the minima.

55. APRA monitors capital adequacy both through analysis of quarterly off-site returns and also through an annual review. External auditors are also required to report annually on the accuracy of data submitted to APRA. The use of specialists from the credit risk unit in the on-site process facilitates cross-institutional consistency. For smaller ADIs, capital adequacy returns may be verified during on-site visits.

56. ECAIs have to be formally recognized by APRA for their ratings to be used by ADIs to risk-weight eligible exposures. APRA has issued guidelines for the recognition of ECAIs, which incorporate the six broad criteria laid out in the Basel II framework. An ECAI may be either directly recognized through APRA's assessment or indirectly recognized through reliance on the assessment of another national supervisor. Currently, APRA has indirectly recognized the ratings of Standard \& Poor's, Moody's, and Fitch, which together account for the majority of rated exposures. ECA country risk scores are not recognized for risk-weighting purposes.

57. Though no ECAIs have been directly recognized, APRA's stipulated process for mapping ECAI ratings to risk weights is based on the method and cumulative default rates (CDRs) detailed in the Basel II Framework. However, the disclosure requirements pertaining to the use of external ratings (paragraph 95 of the Basel II Framework) have not been applied to SA banks, but only to the banks on advanced approaches, given the summary approach to SA disclosure taken in Pillar 3.

58. SA banks can use either the simple or comprehensive approaches to credit risk mitigation. For credit risk mitigation purposes under the SA, APRA recognizes eligible collateral; guarantees from eligible guarantors; mortgage insurance from an acceptable 
lenders mortgage insurers (LMI); credit derivatives from eligible protection providers or where there are eligible arrangements in place; and netting. The main differences in the CRM framework under the SA are that equities that are included in a main index are not recognized as eligible collateral under the simple approach, since they carry a 300 percent risk weight for risk-weighting purposes, and VaR models for calculating haircuts for repo-style transactions in the comprehensive approach have not been permitted, as it is viewed to "provide unnecessary complexity with little additional benefit." A review of the quality and type of collateral used for CRM techniques has been introduced in the supervisory process.

\section{IRB approaches to credit risk}

59. Credit risk is the major risk in the Australian banking system and the five banks on IRB approaches account for about 70 percent of the market. So, effective initial and ongoing implementation of IRB is essential. In achieving high-quality implementation of IRB, as observed by the mission, APRA was able to draw on its robust process for review of credit risk that well-precedes the implementation for Basel II. APRA demonstrated to the mission that it has in place a framework of Basel II-compliant policies, systems, and processes to satisfy itself, as part of its accreditation process and on an ongoing basis, that ADIs manage their credit-risk exposures at a level that is suitable for IRB adoption.

60. This is aided by the bulk of the core team that implemented Basel II being still available and by APRA's efforts to spread the relevant knowledge, skills, and experience to its supervisory teams.

61. However, certain additional focus by APRA is desirable in the face of likely industry pressures to 'optimize' capital. That will help ensure that implementation continues to produce well-capitalized results that APRA considers appropriate.

62. Deviations from the Basel II IRB framework are in the direction of requiring additional capital. The most important is that APRA has set the floor on LGD estimates for residential mortgage exposures at 20 percent, as against Basel II's 10 percent. In addition, APRA has required downturn estimates for much of the credit portfolio, in particular, for corporate and banking exposures. Specialized lending, which is a material portfolio is subject to the supervisory slotting approach (which assigns risk weights that are expected to be more than would be produced by internal models).

63. An extensive in-depth accreditation process was followed. It started in 2005 and proceeded for roughly two years. That permitted extensive analysis and interaction with banks and benchmarking of applications from different ADIs against each other and experience elsewhere. The mission is satisfied that APRA has good reason to believe that advanced banks' IRB rating systems materially meet the minimum requirements of the IRB approach and can be expected to continue doing so on an ongoing basis. 
64. The mission saw considerable evidence of APRA's ability to effectively challenge ADIs' IRB estimates and methodologies, and this was confirmed by banks with whom the mission met. Subsequent analysis of IRB in operation has allowed confirmation that the vast majority of differences between results across portfolios and between ADIs are due to differences in risk.

65. For purposes of ensuring continued compliance by an ADI with the minimum requirements of the IRB approach, APRA has in place comprehensive quarterly off-site analyses of regulatory capital requirements and IRB estimates, including peer group comparisons to identify outliers. There is updated supervisory guidance material for on-site prudential reviews reflecting additional requirements for advanced ADIs. There is also a program of targeted reviews. For example, in 2009 APRA will conduct reviews of the advanced ADIs' stress-testing practices. APRA requires prior approval of material changes to IRB models/estimates. It monitors ADIs' progress in completing the postaccreditation expectations that were set out in their IRB approvals. There is regular review of quarterly reporting of regulatory capital requirements and IRB estimates in APRA's prudential returns, which are subject to annual external audit review on a limited assurance basis.

66. The mission believes that APRA would benefit from including in its supervisory plans periodic detailed drill-down (re-validation and replication) reviews on some portfolios selected on a risk-based fashion (as some other supervisors are doing). That would increase APRA's comfort level with the ongoing robustness of IRB capital measures. It could also plan periodic cross-system reviews of selected key IRB parameters.

67. APRA also requires annual attestations by the Board and CEO that the ADI has identified its key risks; put in systems to monitor and manage those risks; that the riskmanagement systems are operating effectively and adequately for the risks they are designed to control; and that the descriptions of risk-management systems provided to APRA are accurate and current. Any qualifications to the attestation must be noted and corrective actions outlined. APRA reviews the self-assessment material that supports these attestations.

68. The mission discussed with APRA the degree of independence it expected in ADI's IRB validation processes, which are a key Basel II check on the quality of risk estimates and IRB models. ADIs operate validation units that are functionally independent of those using the models, but not always of those designing the models. However, that is not uniformly the case, and it is recommended that APRA consider this expectation for independent validation units.

69. APRA also showed very good understanding of specific matters that are key to assessing IRB models, such as the definition of default used by ADIs, data quality and integrity, and the degree to which risk ratings 'are through the cycle.' APRA, like other supervisors, does not have a complete picture at this stage of the extent to which IRB estimates would move through a credit cycle. 


\section{Operational risk}

70. APRA has implemented the alternative standardized approach and the AMA in Australia. Six banks have been accredited to use the AMA (representing about 75 percent of system assets), while all other ADIs use the ASA. ADIs that adopt the foundation or advanced IRB for credit risk are required to implement the AMA for operational risk. APRA wanted to avoid cherry picking and to promote a consistent, high-quality approach to risk measurement, management, and governance across advanced banks for Pillar 1 risks. In implementing AMA, recognition of insurance mitigation is allowed in APRA's prudential standard, but, to date, no banks have applied for APRA's approval.

71. APRA's decision not to implement the standardized approach in the Basel II operational-risk framework was based on analysis that indicated that the BIA operational risk-capital charge would have been mostly influenced by interest margins, which APRA felt are a better indication of credit risk or other factors. In implementing the ASA, APRA simplified the business lines to three (retail banking, commercial banking, and all other activity) rather than the eight business lines found in the full ASA. As permitted by the Basel II framework, it adopted the highest beta factor for the business lines that were aggregated. This decision was driven by a desire to simplify the regulatory capital calculation for the many smaller credit unions and building societies. As well, APRA's analysis indicated that the resulting capital charge was likely to be appropriate in aggregate and reasonable when compared to the likely results for AMA banks. The Basel framework does not see the ASA as appropriate for large banks and also requires a determination of appropriate qualifying criteria for application of the ASA, which has not been done systematically. The mission suggests that APRA undertake work on specifying these qualifying criteria and, in due course, re-assess the adoption of ASA by the larger standardized banks.

72. AMA banks went through a high-quality accreditation process similar in structure to that for IRB, which started in 2005 and culminated with accreditation decisions at end-2007. APRA had previously had staff supervising certain aspects of operational risk and used these, together with a newly-created analytic capability. As was the case for IRB applicants, AMA applicants had to demonstrate their compliance with APRA's nine pre-requisites relating to the use of risk-based capital and an associated risk-adjusted performance-measurement system. For AMA, as in other jurisdictions, the standards for acceptable methodologies were not as clear as for IRB, and this had to be taken account of in the accreditation process." APRA looked for reasonable challenge and validation processes within banks to ensure quality outcomes.

73. APRA was able to informally benchmark its approach to other countries through its membership in the Basel Committee's AIGOR working group. While APRA was satisfied that the essential elements were in place for AMA banks to allow accreditation, there were a number of areas that it expects to evidence further material improvement. Some of these are the subject of post-accreditation expectations for individual banks or more widespread expectations. 
74. As in other jurisdictions, there are differences across the six AMA banks in the approach to determination of loss frequency and severity, and the approach to determining loss-distribution parameters. For the four major banks, operational risk capital is approximately 3.5 percent to 5 percent of total minimum required capital. This would appear to be less than the result in a number of other jurisdictions (QIS 5 data for group 1 banks was 7.2 percent). APRA should monitor the Australian results in comparison to that in other countries to confirm its overall assessment that the impacts are reasonable.

\section{Market risk and interest rate risk in the banking book}

75. Traded market risk is not large for Australian banks. Based on regulatory information, it accounts for no more than 5 percent to 6 percent of RWA for the major banks and is well less than that in a number of them. In some banks, trading positions would be of moderate complexity. There are seven ADIs with approval to use models for market risk capital charge.

76. APRA has well-developed prudential rules covering all the quantitative and qualitative standards necessary to implement the Basel framework for market risk. In implementing the market risk amendment, APRA benefited from its longstanding involvement with banks in assessing their VAR models. Banks and APRA use stress testing to supplement weaknesses in VAR. They are appropriately gearing up for the further BCBS development of the market-risk rules to deal with weaknesses identified in the recent market turmoil (while complex traded market-risk issues are not pervasive, the market is not immune to the need for sophisticated risk-management approaches, including for counterparty credit risk).

77. There is appropriate reporting to APRA and involvement of specialists in the off-site and on-site supervisory processes to be able to effectively monitor and supervise banks in this area and challenge them as needed.

78. APRA has applied its high-quality approach to accreditation to deal with model approval, including approval of changes to internal model methodologies. The marketrisk team comprises 19 specialists (who also support insurance and superannuation supervision). Based on its observations, the mission agrees with APRA that it has sufficient expertise to satisfy itself that ADIs meet the necessary traded market-risk requirements.

79. APRA has implemented an explicit capital charge for interest rate risk in the banking book (IRRBB) in Pillar 1 for advanced banks. APRA believed this risk was generally larger than traded market risk in Australia and that experience with traded interest rate risk could be relatively easily extended to IRRBB.

80. For standardized banks, APRA treats IRRBB in Pillar 2. Banks with material IRRBB are expected to make an adjustment to their Pillar 1 capital, and APRA uses an outlier framework based on the Basel 200 bps shock to identify ADIs where follow-up or further action is needed. 
81. In the current low-interest-rate environment and given bank's positioning, IRRBB contributes very low or zero levels of capital for major banks, reduced to 2 percent from 3 percent a year ago, but APRA expects this could rise to some 7 percent of RWA at the peak of a cycle.

82. Advanced ADIs are expected to have an appropriate framework to measure, manage, and monitor IRRBB and must model nontraded interest rate risk, using its own internal model. An ADIs model must cover re-pricing and yield curve risks, basis risk, and optionality risk, and must be based on a 99 percent confidence level and one-year holding period.

83. APRA uses a similar extensive approach to accreditation of other models for assessing the qualitative and quantitative aspects of advanced banks' IRRBB. It also requires and assesses appropriate stress tests around key assumptions, such as duration of deposit liabilities, which can have a major impact on IRRBB. APRA staff demonstrated a sound understanding of the issues involved and an ability to effectively challenge banks' approaches.

\section{Securitization}

84. Typically, the big banks do not make use of securitization as a strategic funding instrument, although a few of the other ADIs built their business models around securitization. As a consequence of the global financial crisis, the securitization market has, in effect, closed down with some banks being forced to extend liquidity to certain programs.

85. The regulatory framework aligns with Basel II. APRA staff has a good understanding of related issues. There are some cases where APRA has chosen a more stringent approach, for example, nonzero CCFs for liquidity facilities, regardless of market disruption. APRA has also developed its own treatment for warehouse lending facilities, which is not covered by the Basel II securitization framework. As part of moving to Basel II, APRA ceased the pre-approval of securitization transactions and has adopted a selective supervisory review process.

\section{Assessing Pillar 2}

86. APRA is operating a high-quality supervisory system that meets Basel II Pillar 2 requirements and builds on the robust regulatory and supervisory process already in place prior to Basel II. There is clear evidence of its effectiveness, both on an ongoing basis and in response to specific events, such as the recent global financial crisis. As in other countries, there are areas where APRA should consider enhancements. These could increase the effectiveness of Pillar 2, promote ongoing risk-measurement improvements in banks, and minimize the risk of undetected future deviations by banks from Basel II requirements that might prove problematic. 
87. These enhancements would likely require modest increases in specialist resources, as referred to elsewhere in this document. Additional resources would also allow APRA to have a reservoir to deal effectively with supervision challenges in a Basel II world (which is materially different from under Basel I). There will also be ongoing needs for: special reviews, such as those recently conducted related to stress testing and liquidity management; timely response to banks' need for approval of model and parameter changes; timely consideration of certain matters in the evolution of Basel II rules in Australia that banks and APRA want to pursue; and policy development and implementation in Australia of international Basel II enhancements.

\section{Approach to Pillar 2 implementation}

88. APRA built on and modified its already-robust regulatory and supervisory process in implementing Pillar 2. As in other countries, APRA's Pillar 2 approach was finalized relatively late in the Basel II implementation process and is still evolving. APRA rightly felt it was important to determine Pillar 2 policy once Pillar 1, and its impact, were clearer.

89. Broadly, Pillar 2 implementation entailed adding ICAAP requirements to prudential standards and modifying the supervisory process to formalize determination by APRA of prudential capital ratios (PCR) that are above the Basel minimum, are communicated to ADIs, and are designed to be a floor on ADIs actual capital. APRA considered that its existing supervisory practices for reviewing capital adequacy already complied with Pillar 2 principles.

90. The mission reviewed examples of the operation of the rating and PCR-setting system and examples of supervisory plans. Supervisors, specialists, and managers whom the mission met demonstrated a thorough understanding of individual ADIs and ADI groups, and also of the banking system as a whole. The APRA framework for prudential supervision includes well-developed on-site and off-site supervision and monitoring, and analysis components.

91. APRA's supervisory philosophy and willingness to intervene as necessary to resolve potential problems at ADIs has historically been driven by the recognition that its responsibilities were of additional importance to depositors and to the financial system because of the absence of deposit insurance.

92. APRA is now operating in the 'business as usual' (BAU) environment, where Basel II is integrated into regular activities. Frontline supervisors act as the central coordination point for all Basel II supervisory activities, assisted by subject matter and risk experts from across APRA (credit, market, operational, Basel standards, and interpretation). Most of these specialists were involved in initial accreditation assessments.

93. However, Basel II does require a range of ongoing work that is materially different and more than in a Basel I world. In particular, ADIs are likely to want to adjust model parameters to 'optimize' their capital, which was confirmed by banks that the mission met. Evolution in banks and in the marketplace means there is a need for periodic focused and 
in-depth reviews of the continued appropriateness of how banks are using advanced methodologies for certain portfolios. It will be important to have the capability to do such work in order to reduce the risk that bank capital calculations materially diverge from their risks over time.

94. Basel II supervisory activities in APRA include: quarterly review of ADIs' reporting (extensive for advanced banks) to analyze trends in the drivers of minimum capital; assessment of revisions to risk estimates that ADIs must submit to APRA for approval; follow-up on post-accreditation expectations; review of validation work by ADIs that they do annually; and review of Basel II-specific elements of APRA's supervisory review and risk ratings APRA may also conduct theme reviews that are relevant to Basel II issues, such as the recent reviews of liquidity management and review of major ADIs stress-testing practices relative to new BCBS guidance.

95. More detailed drill-down reviews to assess the continued appropriateness of advanced banks capital and risk measurement are possible under the framework, but their use to date appears to have been limited. In part, this is due to the fact that detailed accreditation assessments were relatively recent and to other priorities in the current environment. It will be important for risk specialists to be able to initiate a limited number of theme reviews periodically, so as to be able to ensure ongoing high-quality implementation of Basel II across major ADIs.

96. ADIs using advanced techniques must provide an annual CEO attestation that they are meeting the IRB and AMA standards. There are internal verification processes in ADIs that APRA plans to review as part of its supervisory process. This is part of ensuring ADIs continue to meet IRB and AMA requirements on an ongoing basis, as required by the Basel II framework. However, these reviews are unlikely to be a substitute for periodic in-depth reviews, at some or all advanced ADIs, of selected models or key risk parameters.

97. In implementing Pillar 2, APRA benefits from the wide involvement of both specialists and supervision staff in the accreditation phase. As a result, supervisory teams have a considerable degree of knowledge and familiarity with Basel II concepts. APRA has also retained roughly 80 percent of the initial dedicated Basel II specialist team, in part assisted by the current market environment, which results in less competition with the private sector for this expertise. The centralization of the risk experts facilitates the development and retention of in-depth knowledge and experience in relation to, amongst other things, Basel II. It also improves consistency in the treatment of ADIs and the interpretation of APRA's requirements.

\section{ICAAPS}

98. As required by Principle 1 of Pillar 2, APRA prudential standards require banks to have ICAAPs and set out the high-level principles, consistent with the Basel II framework, for what they should contain. APRA does not mandate any particular ICAAP format and its requirements are less detailed than in a number of other jurisdictions. Rules require that it 
includes as a minimum: adequate systems and procedures to identify, measure, monitor, and manage the risks arising from the ADI's activities on a continuous basis to ensure that capital is held at a level consistent with the ADI's risk profile; and a capital management plan, consistent with the ADI's overall business plan, for managing the ADI's capital levels on an ongoing basis. ADIs must set a capital target.

99. ICAAPs for major banks are based on their economic capital models and their risk measurement and management processes. Smaller ADIs base their ICAAPs on their regulatory capital, with APRA expecting additional capital for material risks not covered in Pillar 1. APRA reviewed the five major banks' ICAAP submissions in 2008, provided feedback, and is in the process of reviewing ICAAPs for smaller ADIs as part of the supervisory process.

100. Detailed reviews of economic capital models by APRA, including issues of reasonable capital benefit to ADIs of diversification within and across risks, and review of concentration risk have not yet occurred.

101. With respect to Pillar 2 risks for standardized banks, APRA undertakes a (mainly) qualitative assessment of the risks relevant to an ADI, which may impact the ADI's PCR, as noted below. ICAAPs are one element, but far from the most important element, in APRA's assessment of bank's capital in relation to their risk. Some banks that the mission met were unsure as to how their ICAAP figured in the supervisory process.

\section{Supervisory ratings and PCRs}

102. A key element of APRA's implementation of Pillar 2 is its risk assessment/rating system and setting of prudential capital ratios (PCRs) for individual ADIs. APRA's supervisory review process determines an overall rating for each ADI based on consideration of all of its risks and the quality of its management and controls. That rating then feeds into determination of a required prudential capital ratio (PCR) for each ADI. PCRs were added to the supervisory process as part of moving to Basel II.

103. While there is an indicative range of how supervisory ratings translate into PCRs, supervisors are expected to use judgment in setting PCRs, be able to justify their recommendation, and there is an extensive review process. ICAAP targets set by ADIs may influence, but are not determinative in setting PCRs. Normal PCRs for total capital range from a low of 8 percent to 9 percent for low/low-medium risk ADIs to a high of 15 percent for high-risk ADIs. For Tier 1, the expectation is 6 percent to 7 percent for low/low-medium risk banks. ADIs are required by law to meet PCR levels. In general, APRA typically expects them to hold a buffer of 100-200 bps above the PCR, so that normal volatility in capital does not lead to breaches of the PCR. PCRs are confidential to the ADI. As a result of the PCR process, all ADIs are operating above the minimum regulatory requirement. 
104. PCRs essentially cover both Pillar 1 and Pillar 2 risks, so there is no need for separate regulatory capital adjustments for particular Pillar 2 inherent risks. APRA and banks that the mission met indicated that their internal ICAAP target capital levels are close to or less than their PCR. The mission is of the impression that the PCR process is the most important factor determining the actual level of capital held by many ADIs. It is an important bulwark against potential capital declines.

105. Because the actual capital for major banks is close to the PCR, there are incentives for banks to take early action to deal with the capital implications of specific events or evolution of the credit cycle. It is important, therefore, that banks in their capital planning have a good understanding of such matters as to how their actual capital and capital requirements might evolve over a cycle.

106. This system also puts an onus on APRA to justify its PCR numbers. Additional work over time to assess banks' economic capital models might lead to their internally-set targets rising and providing a higher buffer relative to PCRs.

\section{Remedial actions and intervention}

107. APRA's ability to be effective is assisted by legal requirements on banks to notify APRA on where it identifies any breach or prospective breach of its minimum capital adequacy requirements, (including its PCR ratio, which is generally set above Basel II minimums), where the ADI has departed from its own internal ICAAP, where there are concerns with regard to capital adequacy, and when there are any adverse changes in capital. APRA approval is required for any planned reductions in capital. ADIs are also required to notify APRA after they become aware of any breach of a prudential standard or other prudential requirement.

108. APRA is compliant with Basel II in having the full range of formal intervention powers, including issuing directions requiring ADIs to undertake specific actions, to place conditions on a banking authority, and to increase an ADI's PCR (or the proportion of Tier 1 capital), where APRA believes there are prudential reasons to do so. These are in addition to more normal supervisory intervention to deal with identified deficiencies in risk measurement, management, and governance or capital and provisioning issues. The mission saw considerable evidence of APRA's capability and willingness to intervene effectively on a timely basis using a variety of tools.

\section{Other risks}

109. Pillar 2 explicitly involves consideration of risks not covered by Pillar 1, and holding of capital related to those risks. ADI's ICAAP documents must cover the full range of risks, and this is also encouraged by APRA's comprehensive risk-rating system. That also helps supervisors assess the appropriateness of the treatment of these risks by the ADI. As a principles-based regulator, APRA does not mandate a treatment for particular risks, but requires $\mathrm{ADIs}$ to demonstrate that the option they have selected is appropriate for the ADI. 
110. Major risks of that nature in the Australian banking system are credit concentration risk, liquidity risk related to funding profile, and interest rate risk in the banking book. The latter is covered under Pillar 1 in Australia, as noted elsewhere in this assessment. ADIs using the standardized approaches take a mainly qualitative approach to Pillar 2 risks, and a (mainly) quantitative approach through economic capital modeling is taken by ADIs using the advanced approaches. In general, standardized ADIs ensure they have sufficient capital for Pillar 2 risks by operating at a level that is significantly higher than that imposed by APRA.

111. The mission focused on the approach to concentration risk and liquidity risk, which are material, given the structure of the Australian economy and banking system, including the nature of its funding.

112. For concentration risk, advanced ADIs that the mission met demonstrated the ability to use economic capital models to assess the risk, together with extensive limit structures to manage exposure to this risk. It appears that the economic capital allocated to concentration risk is material in banks' economic capital models. APRA has the capability to assess those models, though there is evidence that these resources are stretched by the range of competing priorities, and recent detailed assessments of economic capital models have not yet occurred. APRA also aims to ensure that adequate stress testing is done by advanced and mid-size ADIs for credit concentration risk.

113. Some advanced banks have a capital charge for liquidity risk in their economic capital models, while others do not, on the grounds that dealing with availability of liquid assets and strategies to deal with balance sheet pressures is more important than capital in responding to liquidity risk.

114. APRA has had a sustained focus on liquidity since the global financial crisis began, as part of the multi-pronged effort with the RBA and treasury to deal with this risk to the banking system and wider economy. The mission met with staff involved in the effort; reviewed examples of analysis and monitoring tools used by APRA; reviewed examples of supervisory reviews; and discussed the issue with APRA senior management, RBA, and selected banks. APRA's efforts appeared effective and well coordinated, which will provide a good basis for the planned joint work on macroprudential regulation.

115. Since the global financial crisis began, APRA has focused on how ADIs were managing their liquidity and funding, which is appropriate, given the important nature of this risk to the Australian system. Early on, APRA stepped up liquidity reporting and requested forward-looking funding plans from a range of ADIs. Tracking against these plans is now done via a monthly 'dashboard' that compares various funding indicators for ADIs. APRA established a dedicated team of frontline supervisors and specialist treasury-risk staff to keep in close contact with the treasurers of ADIs, both large and small, during periods of acute market stress. This contact was critical to identifying pressure points. 
116. The improving credit markets in 2009 have enabled APRA to reallocate priorities to ADI funding plans. APRA reviews these plans to identify concentrations of funding sources and any over-reliance on a single source of funding; growth assumptions for both assets and liabilities; the duration of cash-flow mismatches; the spread of funding maturities; contingency planning for sustained market dislocation, not just a single-name event; and modeling of different stress scenarios.

117. The mission saw examples of APRA's supervisory focus in securing required improvements in ADI liquidity risk measurement and management. APRA reports that funding plans and funding management have been improving more generally, in part because of its intervention. It will be important for APRA to ensure that appropriate follow-up occurs to satisfy itself that necessary improvements at ADIs that APRA has identified are in place and working well. APRA could also take stock again, on a system-wide basis, at some point on the improvement to date and whether any further cross-system effort is required. APRA will need to perform continued active monitoring in this area and push selected ADIs to enhance their liquidity plans. There is a risk of ADIs becoming overly reliant on the temporary guarantee and repo arrangements. APRA should require ADIs to consider in their funding plans how they would manage their exit from the temporary arrangements.

118. Going forward, APRA is also revising its standards and guidance to materially enhance its expectations of ADI's liquidity risk management. For example ADIs will be required to have liquidity arrangements that cover a much longer hiatus in markets than the five days now in the requirements. The mission suggests that APRA prioritize the revision of its prudential standard on liquidity.

119. Banks have been taking advantage of the government guarantee of wholesale funding to access markets at longer term than previously. In the short term, this may result in greater absolute amounts of foreign wholesale funding, but in less-volatile tenors. In part because of supervisory actions, liquid asset holdings have risen materially. APRA expects this to continue and that there will be further changes in banks' funding and business models to reduce liquidity risk. This will likely include greater competition for retail deposits and banks adopting less of an asset-side-driven business model.

120. Overall, given the nature of the system and factors, such as reduced access to securitization markets, liquidity and funding risk — while potentially reduced — will remain materially relevant for the Australian system.

\section{Going forward - Matters to consider regarding Pillar 2}

121. Building on the excellent implementation of Pillar 2 to date, going forward, it will be important that APRA:

- $\quad$ ensure that adequate drill-down work related to risk and capital measurement at ADIs, using advanced methodologies, occur as part of the supervisory cycle. Otherwise, there will be a risk that models and measurement systems and risk 
processes that went through a rigorous accreditation process are not updated as necessary for changes in ADI business and in the environment, or ADI optimization of capital parameters over time produces capital results that APRA does not find appropriate. This may require limited additional resources;

- $\quad$ ensure that specialists have adequate input into planning of theme or detailed reviews to verify that banks using advanced techniques are meeting Basel II qualitative and quantitative requirements on an ongoing basis;

- $\quad$ consider enhancing its reviews of ADI economic capital models, given their use in setting target capital and to better understand banks' risk and capital plans, so that APRA can be confident that Pillar 2 risks are adequately covered in the capital targets it is setting;

- $\quad$ enhance its and ADI's analysis of impacts of the economic cycle on available and required capital, so as to be better able to judge the appropriateness of the buffers held by individual institutions; and

- $\quad$ continue to enhance APRA and ADI stress-testing capabilities building on work done to date.

\section{Pillar 3}

122. Pillar 3 disclosure has been implemented, beginning September 30, 2008, through a prudential standard, APS 330. Banks adopted the good practice of organizing a forum through the ABA to provide more harmonization among Pillar 3 disclosures. Several commentators the mission spoke with consider APRA Pillar 3 disclosures for larger banks to be ahead of peers globally.

123. All locally incorporated, Australian-owned IRB/AMA ADIs are subject to annual qualitative and quarterly quantitative disclosures (semi-annual quantitative disclosures are more onerous for these ADIs) and all other locally incorporated ADIs are subject to quarterly quantitative disclosures. Disclosures are to be published on each ADI's website in "a clearly identifiable location," though, in practice, this is not always the case and were located with some effort. Where the ADI does not have its own website, subject to approval by APRA, the disclosures can be made through another medium or in another location. APRA approval is required for nondisclosure of proprietary and confidential information. Pillar 3 disclosures are required to be "appropriately verified" and their 'reliability' attested by the ADI's CEO in the annual declaration. Disclosures do not need to be externally audited, but should be consistent with other audited data provided to APRA or published by the ADI. APRA may require an independent audit. 
124. APRA has made two significant departures from the Basel II framework

(i) ADIs on the advanced approaches have been exempted from the quarterly disclosure requirement of disclosure of components of capital, which can be made semi-annually instead. This exemption has been made in response to the banks' request that they not be subject to quarterly reporting of profits, and such disclosure would enable market analysts to estimate these earnings and pressure them to provide full quarterly disclosure. The domestically owned IRB/AMA ADIs in Australia are listed on the Australian Stock Exchange and half-yearly financial reporting (rather than quarterly) is required for these entities. In general, Australian authorities are comfortable that half-yearly financial reporting balances the need for regular disclosure with the need to avoid an unduly short-term focus. APRA may consider reviewing its Pillar 3 exemption in due course.

(ii) A summary disclosure is required from ADIs subject to the standardized approach (including locally incorporated subsidiaries of foreign-owned banks) in lieu of the detailed disclosures provided in the Basel II framework. The format was devised in consultation with the industry and requires details of capital structure, capital adequacy ratios, and some information on credit exposures by portfolio and related impaired assets to be provided. APRA has taken the view that since these institutions are mainly local and not subject to market scrutiny, such summarized disclosure is appropriate for them.

125. APRA has reviewed Pillar 3 disclosures to ensure compliance with the standard and to reconcile with data submitted in prudential returns and provided feedback where required.

126. The mission supports the measures that APRA is taking to make these disclosures more robust and reliable, and suggests that it goes further in this regard through the following actions (a) the disclosure for banks on the SA should be accompanied by sufficient information to enable the reader to place the disclosure in context; (b) the summary nature of SA disclosure be reconsidered for the listed as well as larger and mid-size SA banks, which are subject and responsive to market discipline; and (c) banks be encouraged to make access to disclosures more prominent, so that they are seen to meet the requirements in both letter and spirit.

\section{Home-host relations for implementing Basel II}

127. The authorities have a clear, well-developed understanding of and approach to homehost issues relevant to them in implementing Basel II and their responsibilities as a host. The system of home-host information sharing, coordination, and cooperation in place is appropriate for the banking system; for the implementation approach for Basel II; and that respects the relevant principles in BCBS home-host documents. While formal MOUs have been entered into with corresponding overseas authorities, cooperation extends beyond formal MOUs and includes evidence of practical arrangements for detailed, specific information sharing on Basel II applications and validation matters, supervisory colleges, and 
occasional joint examinations related to Basel II matters, as well as appropriate decision making with respect to AMA home-host issues. Both APRA and the banks that the mission talked to reported good interaction between APRA and other key jurisdictions in Basel II implementation.

128. Home-host relations between Australia and New Zealand are particularly important, as approximately 90 percent of New Zealand's banking system assets are controlled by the four major Australian banks. Conversely, all four of the major Australian banks are materially exposed to New Zealand risks. APRA and the Reserve Bank of New Zealand (RBNZ) worked closely together during the Basel II project, including on coordinating new prudential standards and staff exchanges. APRA and the RBNZ continue their close supervisory collaboration, with information sharing between the two agencies and jointlystaffed visits to New Zealand banks. 